\title{
IMPLEMENTASI SUPPLY CHAIN MANAGEMENT (SCM) BERBASIS WEB PADA DEPARTEMEN WEAVING I GUNA MENGATASI KETERLAMBATAN HASIL PRODUKSI STUDI KASUS PADA PT ARGO PANTES Tbk
}

\author{
Tri Ika Jaya Kusumawati ${ }^{1}$ \\ Nur Apriyani ${ }^{2}$ \\ Embun Fajar Wati ${ }^{3}$ \\ Universitas Budi Luhur $^{1,2}$, AMIK BSI Tangerang ${ }^{3}$ \\ Jl. Raya Ciledug, Petukangan Utara, Kebayoran Lama, Jakarta Selatan ${ }^{1,2}$, Komplek BSD Sektor XIV-C11 Jl \\ Letnan Sutopo, Kab. Tangerang ${ }^{3}$ \\ Email : tri.ikajaya@budiluhur.ac.id ${ }^{1)}, \underline{\text { nurapriyani.nurap@gmail.com }}{ }^{2)}, \underline{\text { embun.efw @bsi.ac.id }}^{3}$
}

\begin{abstract}
ABSTRAK
Supply Chain Management merupakan salah satu konsep manajemen yang sangat dibutuhkan yang dapat menunjang kegiatan manufaktur pada perusahaan. Setiap proses bisnis internal perusahaan dalam hal ini proses produksi barang membutuhkan penanganan khusus. Proses pembuatan produk dari awal sampai akhirnya menjadi produk yang dapat dijual, sangat membutuhkan proses yang panjang dan waktu yang lama. Proses demi proses yang dilalui kadangkala menghadapi kendala dan masalah. Sehingga proses tersebut menjadi sorotan khusus bagi para pelaku bisnis untuk penanganannya. PT Argo Pantes Tbk merupakan perusahaan yang bergerak dibidang industri tekstil yang menyediakan produk berupa kapas, benang dan kain. Konsep SCM dibutuhkan dalam membantu mengidentifikasi permasalahan yang ada pada PT Argo Pantes Tbk dengan memaparkan masingmasing bagian dari setiap rantai proses manufaktur pada perusahan tersebut, sampai ditemukannya bagian atau titik yang cukup penting dalam kegiatan manufaktur perusahaan tersebut, yaitu proses produksi. Perencanaan produksi merupakan hal yang sangat dibutuhkan bagi perusahaan manufaktur yang meliputi pemenuhan permintaan produksi. Selama ini proses pemenuhan permintaan bahan baku produksi yang berupa benang, permintaan sparepart untuk mesin-mesin produksi pada perusahaan tersebut masih dilakukan secara konvensional, sehingga sering terjadi keterlambatan hasil produksi. Untuk menyelesaikan masalah tersebut, dibutuhkan konsep manajemen produksi yang efektif dan efisien dalam rantai suplai perusahaan. Pembuatan rancangan sistem berbasis web sangat diperlukan untuk keperluan integrasi sistem dengan sistem lainnya. Dengan demikian penggunaan konsep Supply Chain Management (SCM) berbasis web ini dapat menjawab semua permasalahan yang ada dalam rantai produksi pada perusahaan tersebut.
\end{abstract}

Kata Kunci : produksi, supply chain management, pemenuhan permintaan, rantai suplai

\section{PENDAHULUAN}

E-SCM (Electronic Supply Chain Management) muncul sebagai suatu alternatif baru dari pengembangan konvensionalnya dalam mengkoordiasikan aktivitas suplai antara supplier, proses internal sampai pada konsumen akhir. Dengan adanya $e-S C M$, segala fungsi serta proses kerja menjadi lebih mudah dan dapat mengurangi waktu proses sehingga menjadi lebih cepat, efisien dan efektif. E-SCM menggunakan jaringan aplikasi yang mendukung semua proses operasional dari pengadaan bahan baku, pengolahan menjadi barang jadi, pertukaran arus informasi maupun arus fisik berupa barang maupun keuangan dengan memanfaatkan jaringan internet, intranet, ekstranet yang memungkinkan mengakses bagian internal maupun eksternal perusahaan secara online dan realtime[5].

PT Argo Pantes Tbk, yang berlokasi di kota Tangerang merupakan salah satu perindustrian yang bergerak di bidang tekstil. Industri yang memproduksi bahan baku kapas menjadi benang lalu benang diolah menjadi kain. Kegiatan produksi yang tepat waktu sangat 
diperlukan. Namun saat ini proses pengadaan bahan baku yang lambat karena perhitungan bahan baku yang tidak sesuai kebutuhan, banyaknya mesin-mesin yang tidak berfungsi karena proses permintaan sparepart yang lambat, dan kurangnya komunikasi antar bagian.

Dengan demikian diperlukan pendekatan Supply Chain Management (SCM) berbasis web pada Departemen Weaving I yang meliputi sub bagian persiapan, maintenance mesin pada PT Argo Pantes Tbk. Agar dapat melakukan proses produksi tepat pada waktunya serta membantu arus pertukaran infomasi.

Ruang Lingkup Penelitian adalah :

Pada PT Argo Pantes Tbk terdapat ruang lingkup yang luas sehingga untuk mendukung Supply Chain Mangement (SCM) maka penulis membatasi ruang lingkup permasalahan sebagai berikut :

a. Penelitian dilakukan terhadap proses bisnis di Departemen Weaving I yang meliputi sub bagian persiapan dan maintenance mesin, tidak membahas proses pada sub bagian Pertenunan Weaving I, Finishing Weaving I, Gudang Benang, Spinning 3, Logistik, Gudang Grey Dan Gudang Suku Cadang pada PT Argo Pantes Tbk. Dan hanya membahas proses yang berkaitan dengan pemenuhan perhitungan bahan baku, pemenuhan permintaan bahan baku, retur benang, pemenuhan permintaan sparepart mesin dan pemenuhan perbaikan sparepart mesin.

b. Penelitian dilakukan dengan menggunakan metodologi pengembangan sistem informasi yang difokuskan pada analisa dan perancangan sistem Supply Chain Management (SCM) berbasis web sampai pada tahap prototype, tidak sampai membahas implementasi sistem dan evaluasi.

c. Penelitian tidak meliputi proses absensi karyawan, penjadwalan produksi, finishing kain, tenun kain, pendistribusian permintaan sparepart dan penjualan produk.

\section{LANDASAN TEORI}

\subsection{Pengertian Supply Chain Management}

Menurut Punjawan ${ }^{[2]}$ definisi dari supply chain adalah jaringan perusahaan-perusahaan yang bekerja untuk menciptakan dan menghantarkan suatu produk ke tangan pemakai akhir secara bersama-sama. Perusahaan-perusahaan tersebut biasanya pemasok, pabrik, distributor, toko atau ritel, serta perusahaan-perusahaan pendukung seperti perusahaan jasa logistik.

\subsection{Pengertian Electronic Supply Chain Management}

Menurut Turban, et al.(2004 : 302) mengungkapkan : "e-supply chain management adalah kolaborasi penggunaan teknologi untuk meningkatkan proses business-to-business, kecepatan, performa, pengawasan realtime dan kepuasan pelanggan. Hal ini meliputi penggunaan teknologi informasi untukmeningkatkan kinerja aktifitas supply chain sekaligus manajemen supply chain (misalnya perencanaan, koordinasi dan kontrol). E-SCM bukan hanya sekedarmengenai perubahan teknologi, tetapi meliputi perubahan kebijakan manajemen, budaya organisasi, matriks kinerja, proses bisnis, dan struktur organisasi disepanjang supply chain".

\subsection{Pengertian Sistem, Informasi dan Sistem Informasi}

Sistem mempunyai makna yaitu, sesuai kutipan Gary B. Shelly dkk ${ }^{[1]}$ mengungkapkan "Kumpulan dari beberapa komponen yang saling berinteraksi untuk 
mencapai suatu tujuan yang sama."

Sesuai kutipan dari Gary B. Shelly dkk ${ }^{[1]}$ "proses data yang terorganisasi, bermakana serta berguna. "Agar menjadi informasi yang bermanfaat bagi pemakainya, sebuah data harus dapat memenuhi kualitas informasi yang mencakup tiga hal yaitu : akurat, tepat waktu dan relevan. Pengertian sistem informasi menurut Gary B. Shelly $\mathrm{dkk}^{[1]}$ adalah sebagai berikut : "Sekumpulan atau seperangkat hardware, software, data, orang dan prosedur yang saling bekerja sama untuk menghasilkan suatu informasi."

\subsection{Konsep Dasar Analisa dan Perancangan}

Menurut Jogiyanto ${ }^{[6]}$ "analisa sistem adalah penguraian suatu sistem informasi yang utuh ke dalam bagian komponennya yang bertujuan untuk mengidentifikasikan dan mengevaluasi permasalahan, kesempatan, hambatan yang terjadi dan menentukan kebutuhan sehingga dapat diusulkan perbaikannya”.

\section{METODOLOGI PENELITIAN}

\subsection{Tahapan Penelitian}

Adapun alur tahapan penelitian yang dilakukan adalah sebagai berikut :

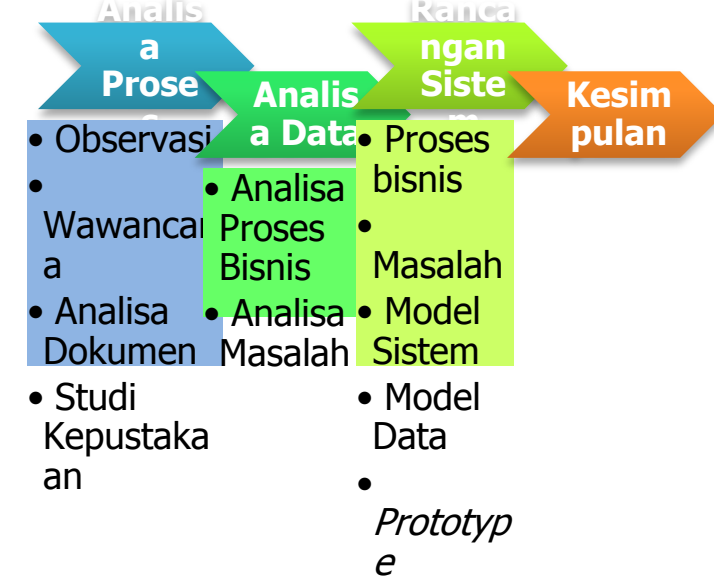

Gambar 1: Alur Tahapan Penelitian

\subsection{Analisa Proses Bisnis}

Analisa proses bisnis dilakukan untuk mengetahui alur kegiatan pada PT Argo Pantes Tbk. Hasil analisa proses bisnis kemudian dituangkan dalam bentuk rich picture menggunakan software Edraw.

\subsection{Analisa Data}

Setelah mengetahui proses bisnis, maka akan diketahui masalah yang terjadi. Selanjutnya akan dibuat menggunakan fishbone diagram dapat dibuat menggunakan software Microsoft Visio 2007.

\subsection{Perancangan Sistem Usulan}

Dalam merancang sistem usulan, untuk pemodelan sistem digambarkan dengan menggunakan use case diagram dan activity diagram. Sedangkan pemodelan data, 
menggunakan Entity Relationship Diagram (ERD). Untuk gambar pemodelan sistem, dibuat menggunakan Rational Rose 2003. Sedangkan gambar pemodelan data seperti ERD dibuat dengan menggunakan Microsoft Visio 2007.

\section{PEMBAHASAN}

Proses ini dimulai oleh Bag. PPC (Product Planning Control), setiap bulannya akan memberikan rencana tenun ke Ka.Departemen Weaving I. Selanjutnya Bag. PPC akan memberikan Delivery Order (DO) ke Gudang Benang agar mempersiapkan kebutuhan benang untuk produksi setiap bulan. Lalu Bag. PPC memberikan tembusan DO ke Bag. Persiapan Weaving I sebagai acuan pengambilan benang ke gudang benang. Setelah menerima DO yang diberikan, maka Bag. Persiapan Weaving I membuat Nota Permintaan Benang (NPB). Dan Bag. Persiapan Weaving I membuat stock benang untuk mengetahui jumlah benang yang masih tersedia setiap harinya. Bag. Persiapan Weaving I membuat Nota Retur Benang (NRB) untuk benang-benang yang mengalami cacat. Selanjutnya Pada Bag. Maintenance Weaving I membuat kartu stock setiap bulannya, untuk mengetahui jumlah stock sparepart yang ada. Bag. Maintenance Weaving I dalam melakukan kegiatan maintenance mencatatnya pada buku maintenance. Dan Bag. Maintenance Weaving I dapat membuat Order Perbaikan Barang (OPB) untuk sparepart yang harus diperbaiki, membuat Order Pembelian Lokal (OPL) untuk sparepart yang harus dibeli berdasarkan buku maintenance. Untuk melihat proses tersebut, dapat dilihat pada gambar 2 :

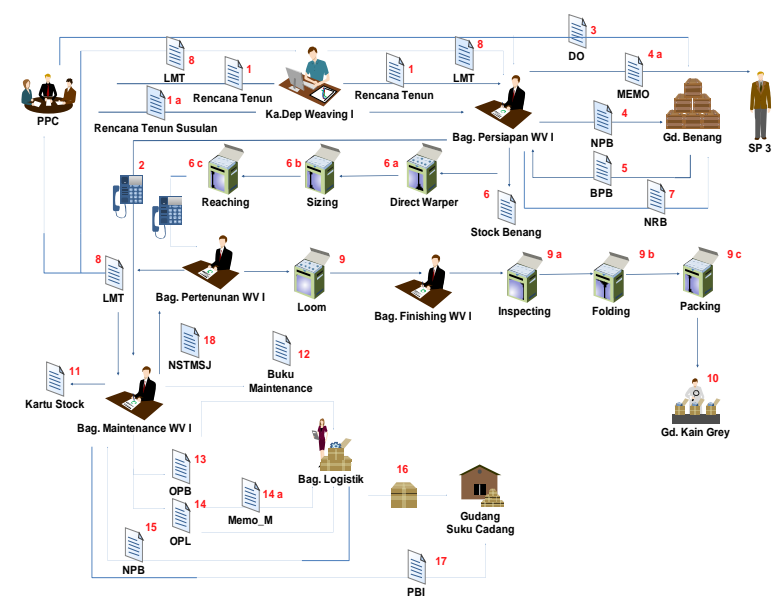

Gambar 2. Rich Picture Proses Bisnis Bag. PPC

\subsection{Identifikasi Masalah}

Dengan memahami proses bisnis, dapat diketahui masalah yang terjadi beserta penyebab-penyebabnya. Masalah tersebut adalah hasil produksi terlambat. Untuk lebih memahami, dapat dilihat pada gambar 3. berikut :

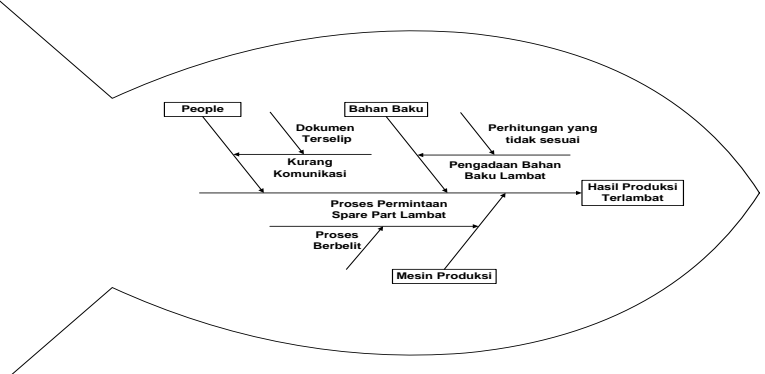

Gambar 3. Cause Effect Diagram ${ }^{[4]}$ 
Penjelasan gambar :

-Komunikasi

Komunikasi antar bagian tidak berjalan dengan lancar disebabkan oleh lambatnya informasi yang diterima antara bagian yang satu dengan bagian lainnya karena adanya dokumen yang terselip atau hilang.

-Bahan Baku

Pengadaaan bahan baku yang lambat, dikarenakan adanya perhitungan bahan baku yang tidak sesuai untuk kebutuhan produksi pada Bag. Persiapan Weaving I.

-Mesin Produksi

Lambatnya proses permintaan sparepart, karena membutuhkan waktu yang cukup lama dalam mendapatkan persetujuan dari pihak-pihak yang terkait.

\subsection{Identifikasi Kebutuhan}

Sebelumnya, perlu ditelusuri kebutuhan dari sistem yang ingin dirancang. Kebutuhankebutuhan itu antara lain: Data karyawan, data user, data anyaman, data benang, data bahan, data mesin, data sparepart, data rencana produksi, data delivery order, data persentase, data nota permintaan benang, data retur benang, data stock benang, data maintenance, data stock sparepart, data order perbaikan barang, data order pembelian barang, laporan grafik produksi, laporan stock benang, laporan retur benang, laporan kondisi mesin, laporan stock sparepart.

\subsection{Use Case Diagram}

Penggambaran fungsionalitas sistem dapat terlihat pada use case diagram. Dan dengan identifikasi kebutuhan maka dapat dibuat use case diagram Yang dijelaskan pada gambar dibawah ini.

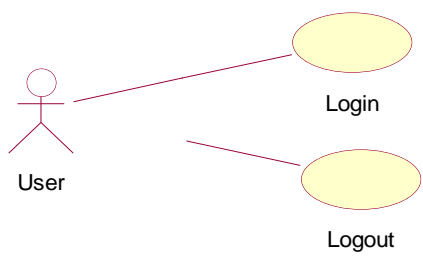

Gambar 4. Use Case Diagram Login

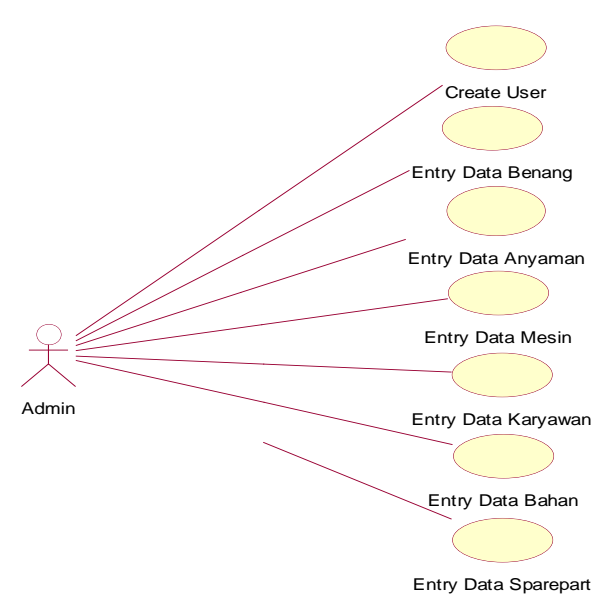

Gambar 5. Use Case Diagram Data Master 


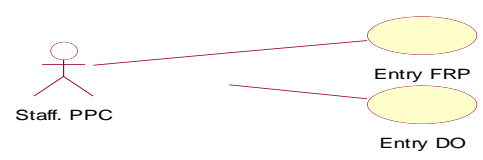

Gambar 6. Use Case Diagram Pemenuhan Produksi

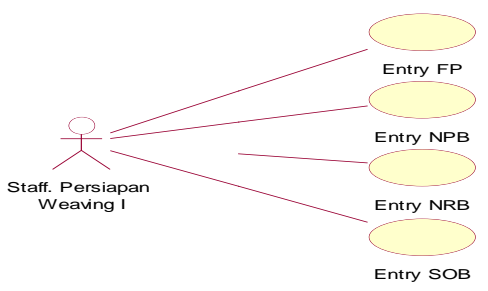

Gambar 7. Use Case Diagram Transaksi Produksi

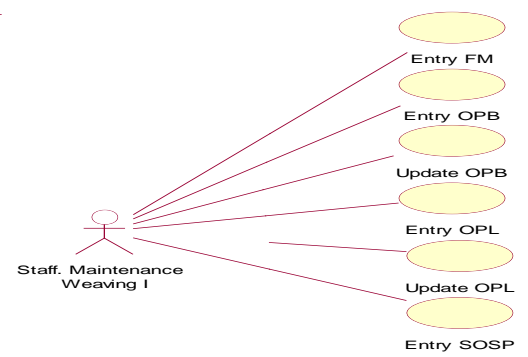

Gambar 8. Use Case Diagram Transaksi Maintenance

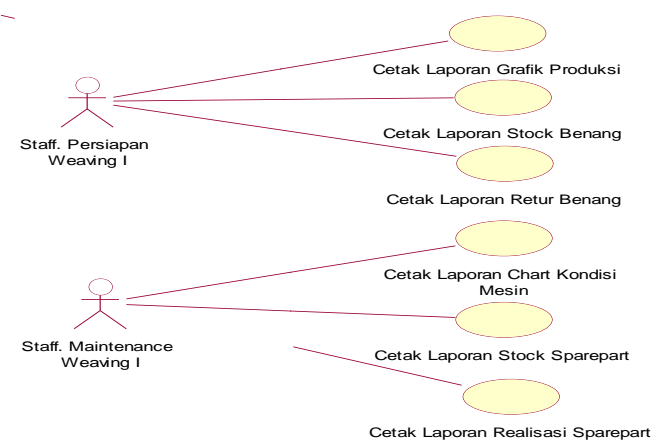

Gambar 9. Use Case Diagram Pembuatan Laporan

\subsection{Activity Diagram}

Untuk memudahkan dalam menjelaskan proses bisnis dari sistem usulan yang dibuat, proses bisnis sistem usulan dibagi menjadi beberapa bagian proses dengan menggunakan activity diagram.

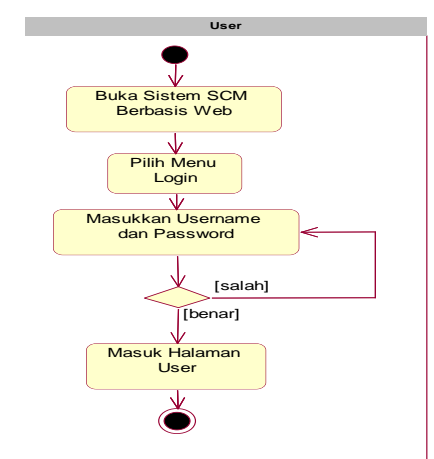

Gambar 10. Activity Diagram Login 


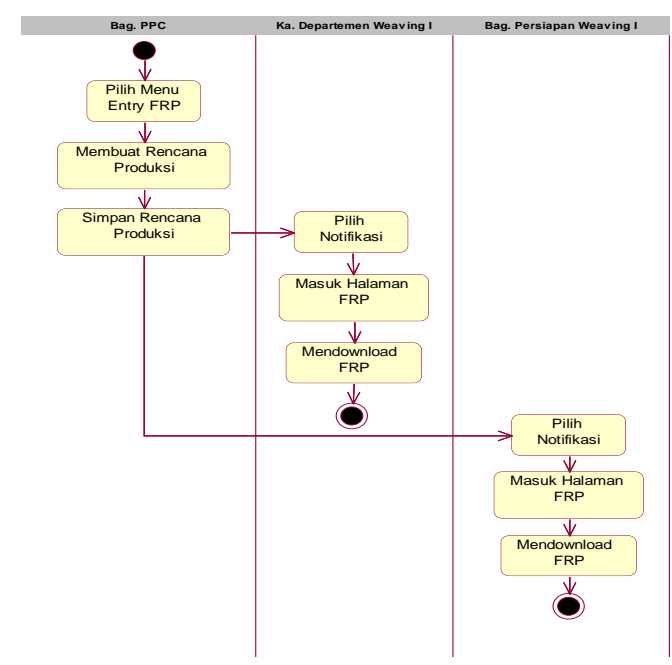

Gambar 11. Activity Diagram Pembuatan Rencana Produksi

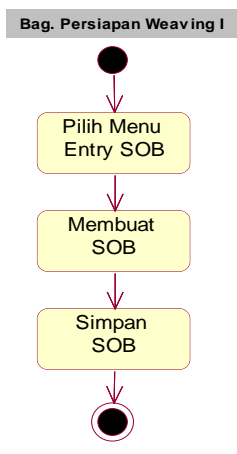

Gambar 13. Activity Diagram Stock Opname Benang

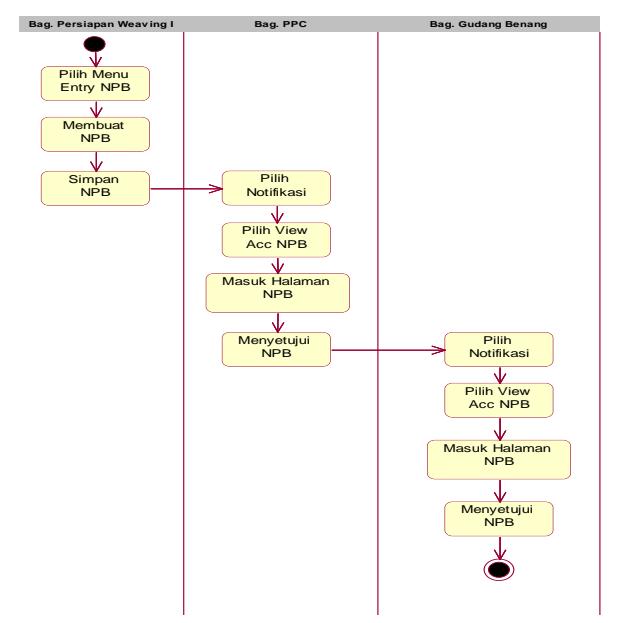

Gambar 14. Activity Diagram Proses Pembuatan NPB 


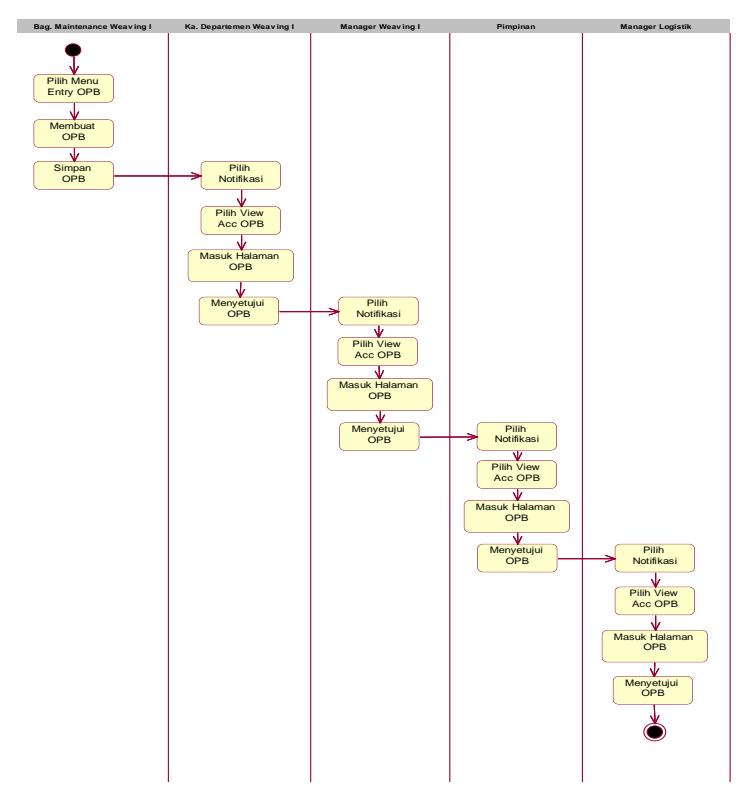

Gambar 15. Activity Diagram Proses Pembuatan OPB

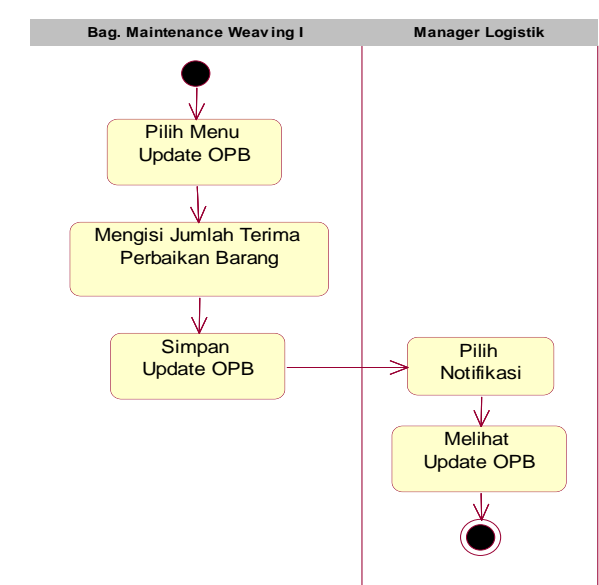

Gambar 16. Activity Diagram Proses Update OPB

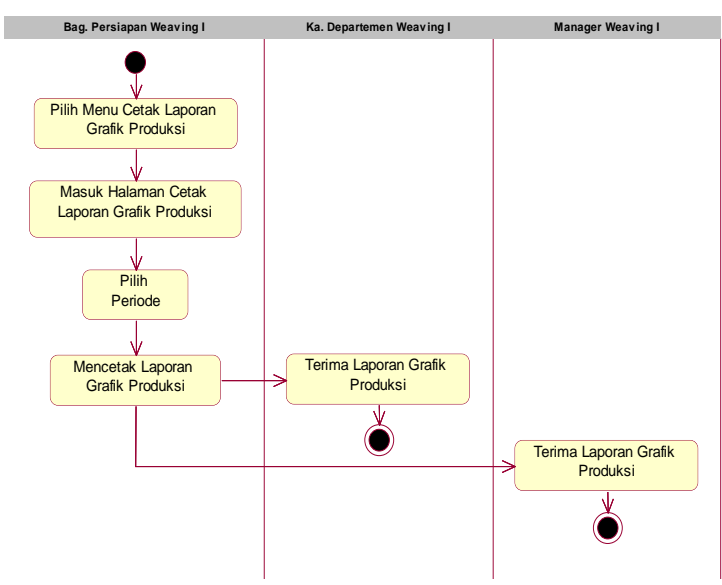

Gambar 17. Activity Diagram Pembuatan Laporan Grafik Produksi

\subsection{Entity Relationship Diagram}

Model data digambarkan dengan Entity Relationship Diagram yang dapat dilihat pada gambar 18 berikut: 


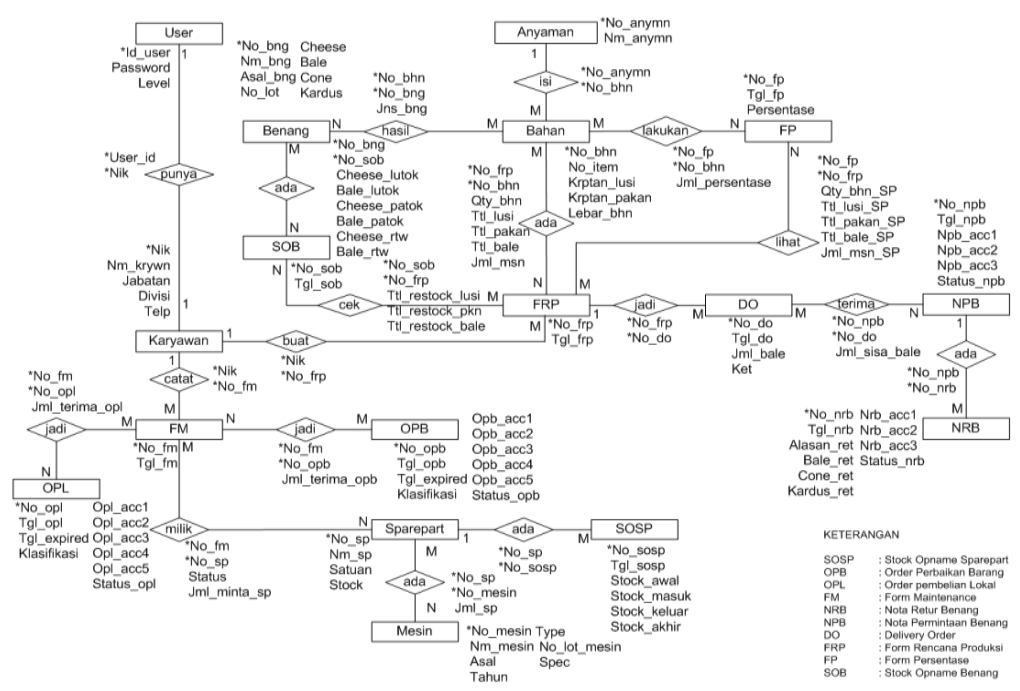

Gambar 18. ERD (Entity Relationship Diagram)

\subsection{Rancangan Antar Muka}

Pada gambar 18 dapat dilihat struktur menu dari rancangan sistem usulan

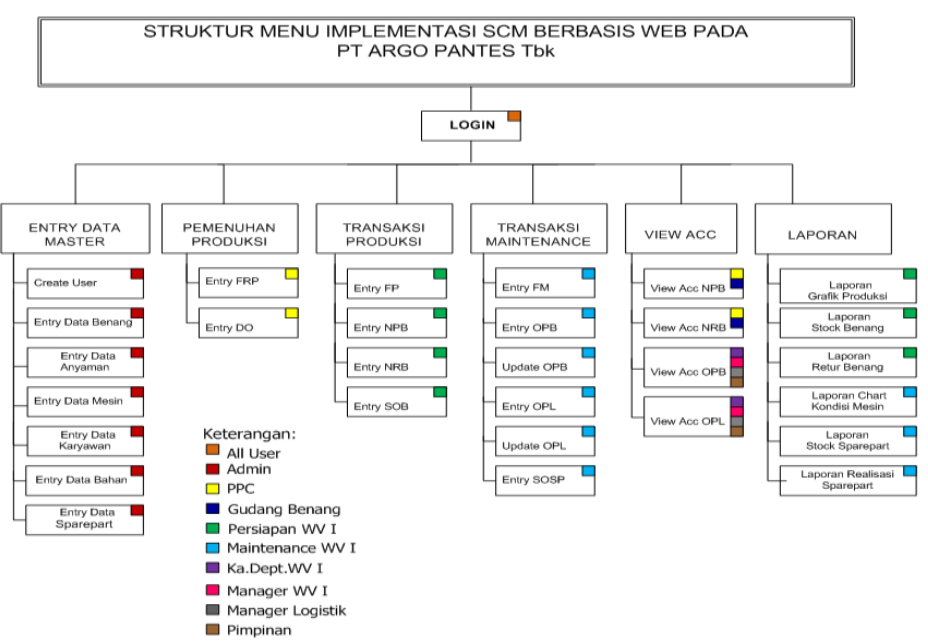

Gambar 19. Struktur Tampilan Rancangan Layar

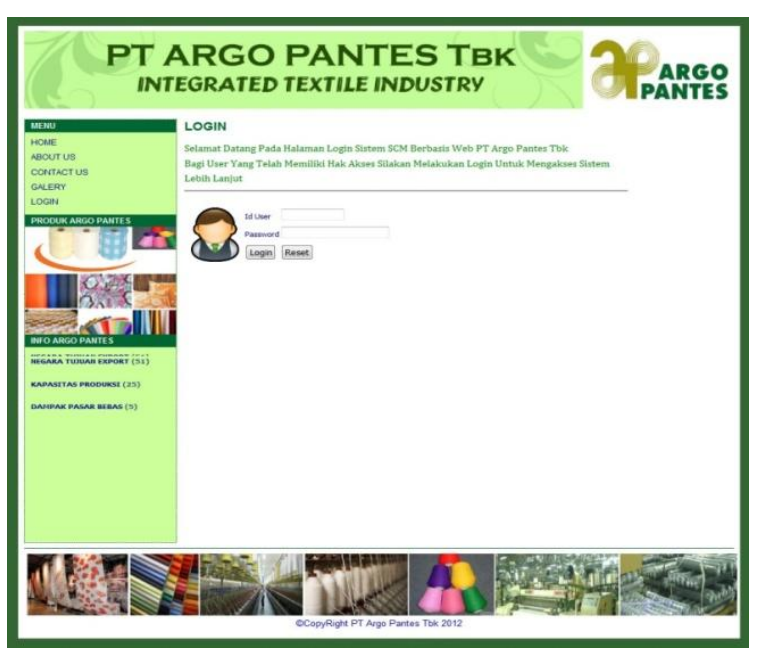

Gambar 20. Halaman Login 


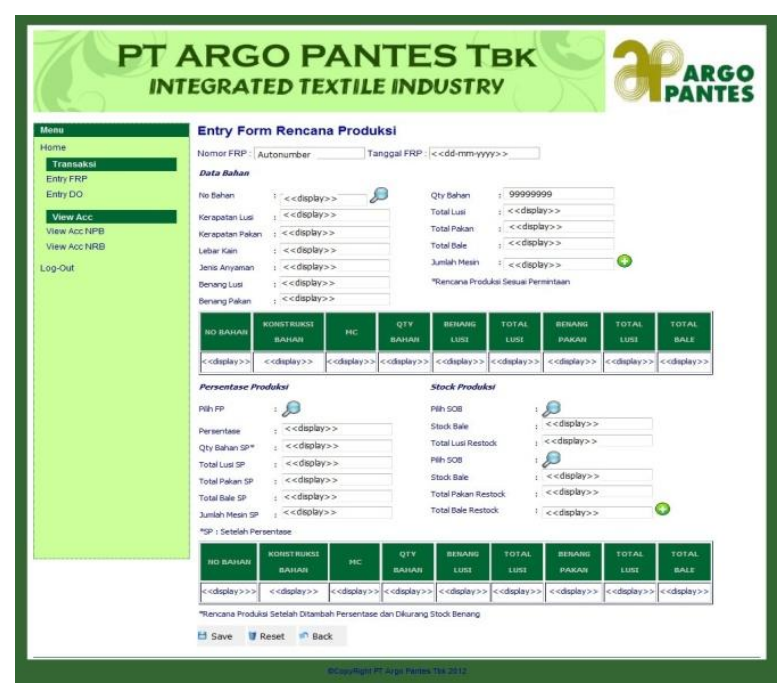

Gambar 21. Halaman Entry Form Rencana Produksi

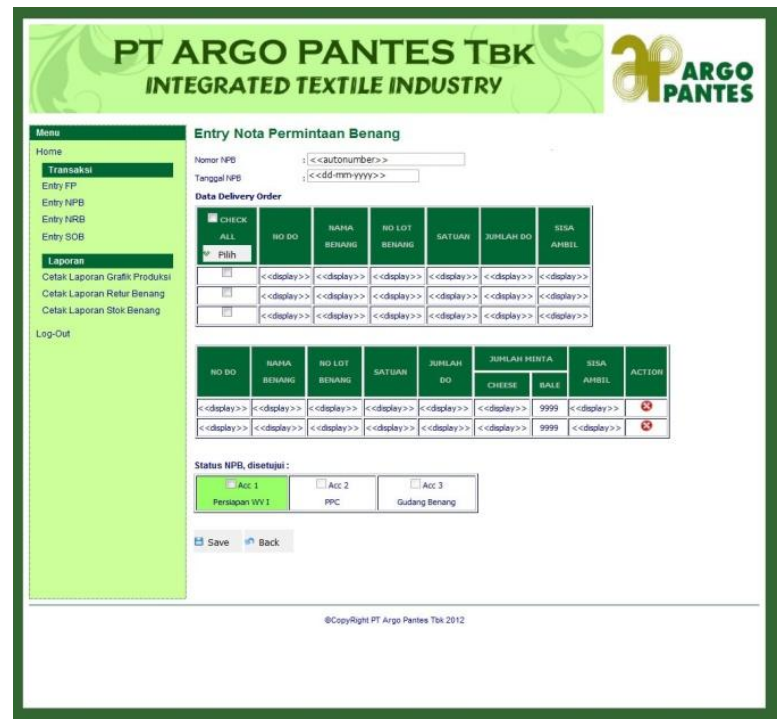

Gambar 22. Halaman Entry Nota Permintaan Benang

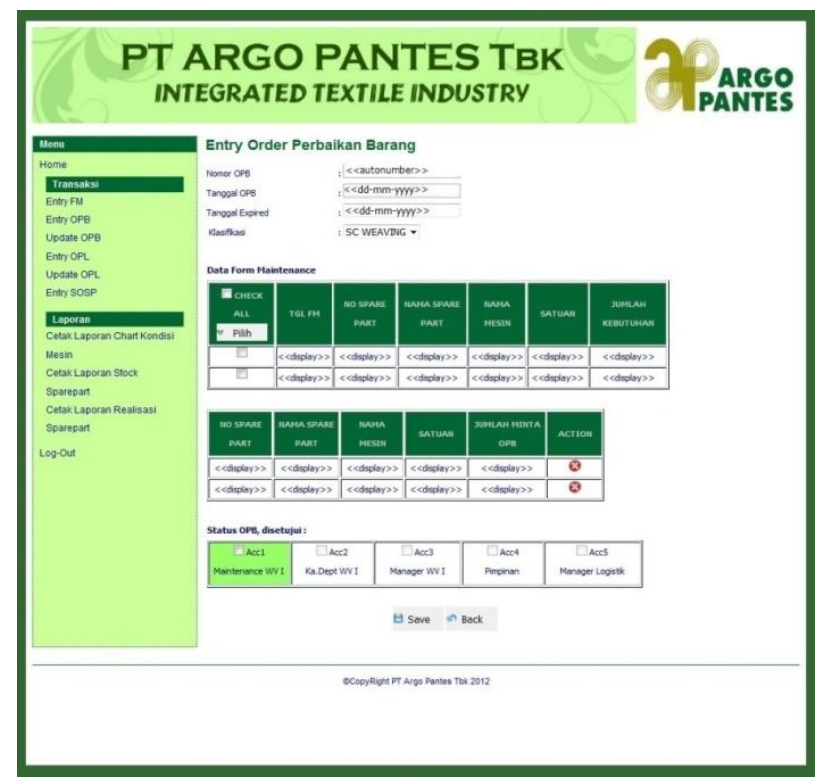

Gambar 23. Halaman Entry Order Perbaikan Barang 


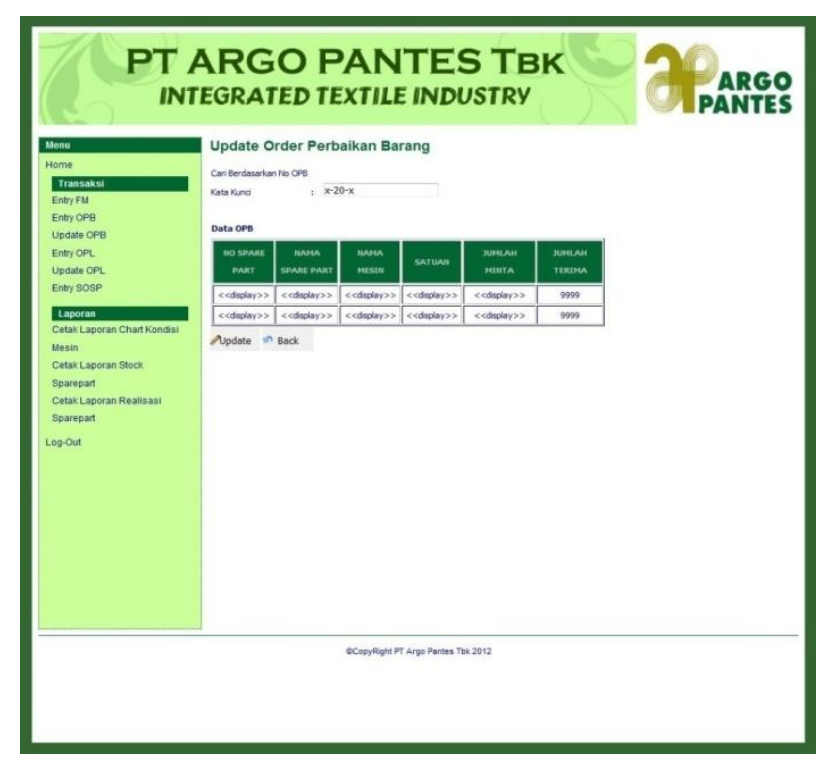

Gambar 24. Halaman Update Order Perbaikan Barang

\section{KESIMPULAN}

Berdasarkan penelitian dan perancangan yang telah dilakukan pada PT Argo Pantes Tbk, maka dapat diambil kesimpulan sebagai berikut :

a. Dengan menggunakan penerapan Supply Chain Management (SCM) berbasis web, dapat mengurangi tingkat kesalahan yang disebabkan oleh human error seperti dokumen terselip, perhitungan rencana produksi yang tidak sesuai.

b. Dalam membantu menyelesaikan masalah di bagian persiapan pada Departemen Weaving I PT Argo Pantes Tbk, perlu dibuatkan interface pemenuhan permintaan bahan baku produksi berupa benang agar memperlancar proses produksi dari segi dokumentasi dan manajamen sumber daya.

c. Dalam membantu menyelesaikan masalah di bagian maintenance pada Departemen Weaving I PT Argo Pantes Tbk, perlu dibuatkan interface pemenuhan permintaan sparepart sehingga dapat mengatasi ketidakberadaan pihak-pihak yang berwenang untuk persetujuan dokumen.

d. Dengan adanya sistem ini, dapat membantu para manager dan pejabat tinggi lainnya dalam mengambil keputusan yang diperoleh dari hasil keluaran sistem dalam bentuk laporan yang informatif dan cepat.

\section{SARAN}

Berdasarkan penelitian yang telah dilakukan, maka dapat dilakukan saran-saran sebagai berikut :

a. Manajemen PT Argo Pantes Tbk, dapat terus mendukung pengembangan dan pemanfaatan teknologi informasi dalam operasional bisnis sehari-sehari.

b. Rancangan sistem aplikasi Supply Chain Management (SCM) berbasis web yang dibuat diharapkan dapat dikembangkan kembali oleh PT Argo Pantes Tbk untuk meningkatakan efisiensi dan kecepatan arus informasi antara Departemen Weaving I dengan bagian-bagian terkait lainnya.

c. Agar terlaksananya sistem ini dengan baik, diharapkan adanya proses pelatihan dan kerjasama yang baik antara sub bagian yang terlibat dalam sistem ini.

d. Penambahan fungsi-fungsi tertentu sangat perlu diperhatikan dan dibutuhkan dalam 
proses pengembangan sistem nantinya. Sehingga fungsionalitas dari sistem ini menjadi semakin meningkat sesuai dengan kebutuhan user.

\section{DAFTAR PUSTAKA}

[1] Shelly, B. Garry., Harry J. Rosenblatt. System Analysis And Design, Eighth Edition Canada: Course Tecnology, 2010.

[2] Chopra, sunil and meindl, peter. Supply Chain Management: Strategy, planning, and operational. New Jersey: Prentince Hall, 2001

[3] Indrajit dan Richardus Djokopranoto. Konsep Supply Chain Management: cara baru memandang mata rantai penyediaan barang. Jakarta: Grasindo, 2006.

[4] Ishikawa Fishbone, http://hardipurba.com/2008/09/25/diagram-fishbone-dareiishikawa.html 16:52 21/12/2012.

[5] Teori Produksi, http://www.sarjanaku.com/2012/12/pengertian-produksi-luasmenurut-para.html 17:05 20/12/2012.

[6] Jogianto. Analisis dan Desain. Yogyakarta: Graha Ilmu, 2005. 